\title{
Study on the Matching Relationship between Polymer Hydrodynamic Characteristic Size and Pore Throat Radius of Target Block S Based on the Microporous Membrane Filtration Method
}

\author{
Li Yiqiang, Gao Junxin, Yin Dandan, Li Junjian, and Liu Hualong \\ China University of Petroleum, Beijing 102249, China \\ Correspondence should be addressed to Gao Junxin; gaojunxin2007@126.com
}

Received 1 July 2013; Revised 14 January 2014; Accepted 16 January 2014; Published 19 March 2014

Academic Editor: Stavros Lalas

Copyright (C) 2014 Li Yiqiang et al. This is an open access article distributed under the Creative Commons Attribution License, which permits unrestricted use, distribution, and reproduction in any medium, provided the original work is properly cited.

\begin{abstract}
The concept of the hydrodynamic characteristic size of polymer was proposed in this study, to characterize the size of aggregates of many polymer molecules in the polymer percolation process. The hydrodynamic characteristic sizes of polymers used in the target block $\mathrm{S}$ were examined by employing microporous membrane filtration method, and the factors were studied. Natural core flow experiments were conducted in order to set up the flow matching relationship plate. According to the flow matching plate, the relationship between the hydrodynamic characteristic size of polymer and pore throat radius obtained from core mercury injection data was found. And several suitable polymers for different reservoirs permeability were given. The experimental results of microporous membrane filtration indicated that the hydrodynamic characteristic size of polymer maintained a good nonlinear relationship with polymer viscosity; the value increased as the molecular weight and concentration of the polymer increased and increased as the salinity of dilution water decreased. Additionally, the hydrodynamic characteristic size decreased as the pressure increased, so the hydrodynamic characteristic size ought to be determined based on the pressure of the target block. In the core flow studies, good matching of polymer and formation was identified as polymer flow pressure gradient lower than the fracture pressure gradient of formation. In this case, good matching that was the pore throat radius should be larger than 10 times the hydrodynamic characteristic size of polymer in this study. Using relationship, more matching relationship between the hydrodynamic characteristic sizes of polymer solutions and the pore throat radius of target block was determined.
\end{abstract}

\section{Introduction}

Polymer flooding is a quite advanced technique for enhancing oil recovery. For polymer flooding, the water-soluble polymers are used for increasing the injection liquid viscosity to improve the mobility ratio and reduce water phase permeability, so as to enhance the oil recovery [1-4].

The effect of polymer flooding can be strengthened by using high molecular weight and high concentration of polymer, but except for the molecular weight and concentration of polymer, the size of the polymer is related to some other factors, such as the dilution water, injection pressure, and viscosity. If the polymer is designed oversize, it is easy to cause plugging in the formation, which makes the polymer solution difficult to be injected. Thus, for the polymer flooding, the polymer which has good relation with the pore throat size should be selected [5-8].

The matching relation between HPAM (partially hydrolyzed polyacrylamide) KYPAM-II and the pores of nuclepore film was investigated using nuclepore film filtration, scanning electron microscope, and dynamic light scattering [9]. The results indicated that, when the polymer KYPAM-II solution passed through nuclepore films with different pore diameters, the figure of the filtration curves, the solution viscosity and concentration before and after filtration, and the size variation of the solution molecular clews differed.

The matching relation between the molecular size of polymers and the pore size of Karamay conglomerate reservoir in Xinjiang oil field was studied. By employing the nuclepore film filtration method, core flooding experiments, and 
TABLE 1: Dilution water composition.

\begin{tabular}{lcccccccc}
\hline Dilution water & $\mathrm{Cl}^{-}$ & $\mathrm{SO}_{4}{ }^{2-}$ & $\mathrm{HCO}^{3-}$ & $\mathrm{CO}_{3}{ }^{2-}$ & $\mathrm{K}^{+}+\mathrm{Na}^{+}$ & $\mathrm{Ca}^{2+}$ & $\mathrm{Mg}^{2+}$ & Total salinity, mg/L \\
\hline A & 54.79 & 31.41 & 236.61 & 15.51 & 68.92 & 41.5 & 18.55 & $\mathbf{4 6 7 . 2 8}$ \\
$\mathrm{B}$ & 812.65 & 20.94 & 2886.58 & 186.15 & 1700.14 & 45.87 & 7.95 & $\mathbf{5 6 6 0 . 2 9}$ \\
\hline
\end{tabular}

dynamic light scattering method, the molecular size of several candidate polymers for the pilot test was examined, and several suitable polymers for different reservoirs permeability were obtained [9].

In this study, by employing the microporous membrane filter method under the experimental pressure without affecting the size value, the hydrodynamic characteristic sizes of polymers with different molecular weights, concentrations, and dilution water were determined. Combined with the formation pore throat size obtained from mercury curves, polymers suited for different permeability formations of the target block $\mathrm{S}$ were given.

Matching relationship was obtained based on natural core flooding study. Different polymer was injected to natural cores, some occurred plugging and some did not. How many times polymer hydrodynamic characteristic size larger than pore throat radius would not cause plugging was summarized. According to the relationship, more polymer hydrodynamic characteristic sizes were determined; larger relationship plate between polymer hydrodynamic characteristic size and pore throat radius was made. It was thought that polymer hydrodynamic characteristic plate is a promotion on the basis of flow plate, and more energy and time to conduct the core flow experiments are saved because polymer hydrodynamic characteristic size is easier to measure. This method can be used in any target oilfield. Different block has different matching criteria. Certainly more flow experiments are conducted; more accurate matching relationship between the hydrodynamic characteristic size of polymer and pore throat size is drawn, and more reliable are the hydrodynamic characteristic matching relationship plates.

\section{Experiment}

2.1. Materials. Natural sandstone cores from target block $S$ were used to conduct the study. The cores were cut into cylindrical shape with $2.5 \mathrm{~cm}$ diameter and length ranged from $7 \mathrm{~cm}$ to $10 \mathrm{~cm}$.

Polymer HPAM (partially hydrolyzed polyacrylamide) produced by Beijing Hengju company was used in this study. Solid content of polymer was $88 \%$. Molecular weights were $800 \times 10^{4}, 1500 \times 10^{4}, 1700 \times 10^{4}$, and $2500 \times 10^{4}$. To simulate borehole shearing, the polymer solutions were sheared by Warring shearing device. Shear standard was to make viscosity retention of polymer with molecular weight of $1500 \times 10^{4}$ and concentration of $1500 \mathrm{mg} / \mathrm{L}$ to $40 \%$.

Two kinds of formation brines were used in this study for saturation of the core and aqueous solution preparation. Salinity was, respectively, $467.28 \mathrm{mg} / \mathrm{L}$ and $5660.29 \mathrm{mg} / \mathrm{L}$; compositions were shown in Table 1.

\subsection{Methods}

\subsubsection{Polymer Solution Preparation Procedure}

(i) Polymer mother solution with concentration of $5000 \mathrm{mg} / \mathrm{L}$ was first prepared. Stir for 2 hours with a speed of $400 \mathrm{rev} / \mathrm{min}$ was required. Every time preparation volume was $200 \mathrm{~mL}$, and each dilution water needs one mother solution.

(ii) Stand for more than 4 hours for aging.

(iii) The purpose solution was prepared by diluting the mother solution to purpose concentration. Stir for 2 hours with a speed of $200 \mathrm{rev} / \mathrm{min}$ was required.

(iv) Viscosity before and after shearing was measured at a temperature of $45^{\circ} \mathrm{C}$.

(v) This was followed by the polymer hydrodynamic characteristic size determined.

2.2.2. Microporous Membrane Filtration Method. The microporous membrane filtration apparatus appears in Figure 1. The apparatus was placed in a constant temperature oven of $45^{\circ} \mathrm{C}$. Polymer solution was put into the container with every time $50 \mathrm{~mL}$. At a constant pressure, the polymer solution passed through a membrane with successive diameters of $2.0 \mu \mathrm{m}, 1.2 \mu \mathrm{m}, 1.0 \mu \mathrm{m}, 0.8 \mu \mathrm{m}, 0.65 \mu \mathrm{m}, 0.45 \mu \mathrm{m}, 0.3 \mu \mathrm{m}$, and $0.22 \mu \mathrm{m}$. Experiments continued till retained aggregation was observed on the microporous membrane.

The viscosity and concentration of the polymer solution before and after filtration were measured, and the polymer hydrodynamic characteristic size was defined as the size of the membrane pore corresponding to the sharp point of viscosity and density curves; one case was presented in Figure 2.

2.2.3. Core Flood Studies. A core flood apparatus was built to simulate fluid flow in porous media in the reservoir. A pump (2PBOOC advection pump) was connected to two accumulators to deliver brine and polymer solutions. Accumulators were connected to the core holder, which can accommodate a core sample with diameter $2.5 \mathrm{~cm}$ and length up to $10 \mathrm{~cm}$. Pressure transducers were used to measure the pressure drop across the core. Data acquisition system was used to collect data from the pressure transducer. One oven was used to provide temperature controlled environment.

The following are the steps for core flow experiments.

(i) Core samples were extracted with toluene.

(ii) Core samples were dried overnight in the $100^{\circ} \mathrm{C}$ oven.

(iii) Gas permeability of the core was measured. 


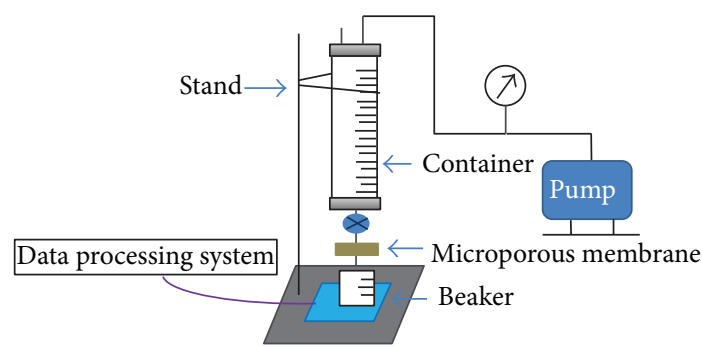

FiguRE 1: Apparatus of microporous membrane filtration.

Molecular weight $1500 \times 10^{4}$, concentration $1500 \mathrm{mg} / \mathrm{L}$-dilution water A

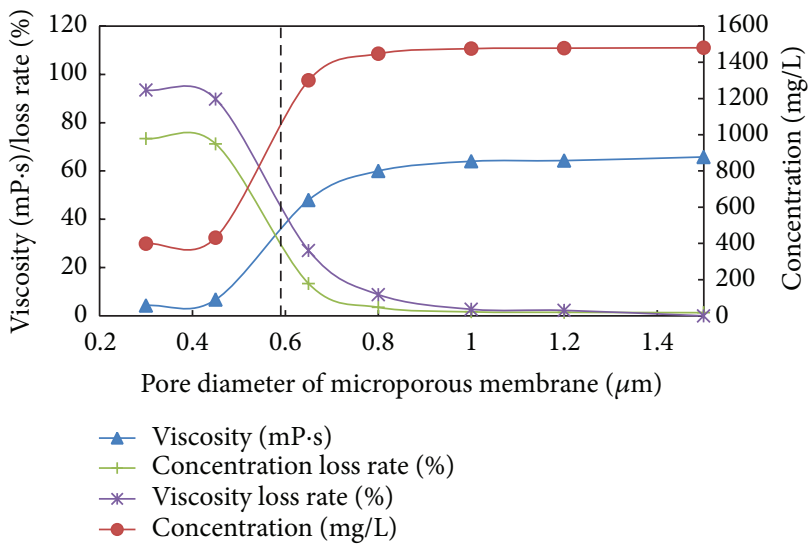

FIGURE 2: Concentration and viscosity of polymer and their loss rate with different diameters of microporous membrane.

(iv) Core samples were vacuum saturation of water for 8 hours.

(v) Core sample was loaded to the core holder and confining pressure $0.3 \mathrm{MPa}$ was applied.

(vi) Water permeability was measured using different flow rates $0.5,1,2,4$, and $8 \mathrm{~mL} / \mathrm{min}$.

(vii) Core holder was put in the $45^{\circ} \mathrm{C}$ oven for at least 2 hours.

(viii) Polymer solution was injected with flow rate $0.2 \mathrm{~mL} / \mathrm{min}$. Polymer flooding continued till the experimental pressure and export flow rate became constant. Pressure was recorded in this process.

\section{Results and Discussion}

3.1. The Hydrodynamic Characteristic Size of Polymer and Its Influencing Factors. Figure 3 shows the hydrodynamic characteristic size of polymer with different pressure. The hydrodynamic characteristic size of polymer remained constant at a pressure of less than $0.05 \mathrm{MPa}$, but it suddenly decreased as the pressure increased to more than $0.1 \mathrm{MPa}$. One possible explanation for this was that molecular coils of the polymer were compressed by extrusion pressure. In order to both save experimental time and get the largest hydrodynamic characteristic size of polymer to study the

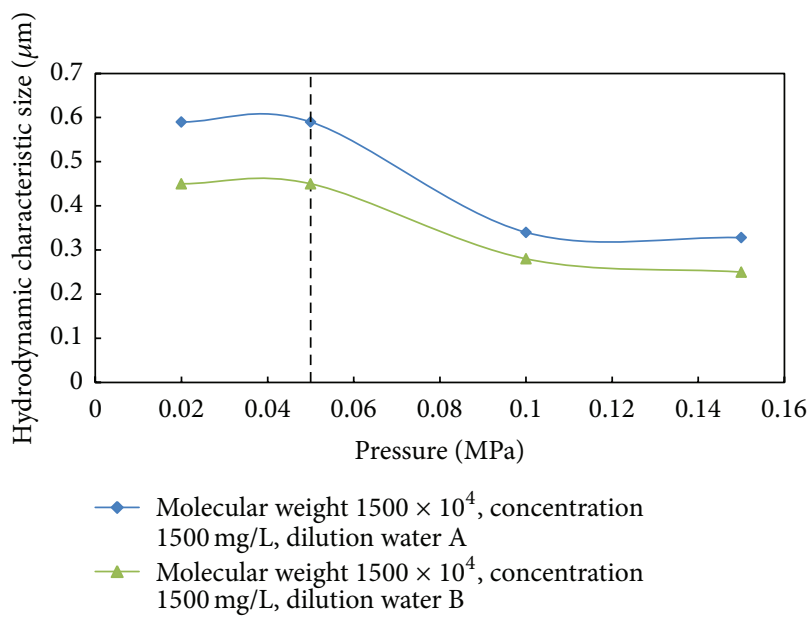

FIGURE 3: In order to both save time and achieve the biggest hydrodynamic characteristic size of polymer to study the matching relationship, a pressure $0.05 \mathrm{MPa}$ was selected.

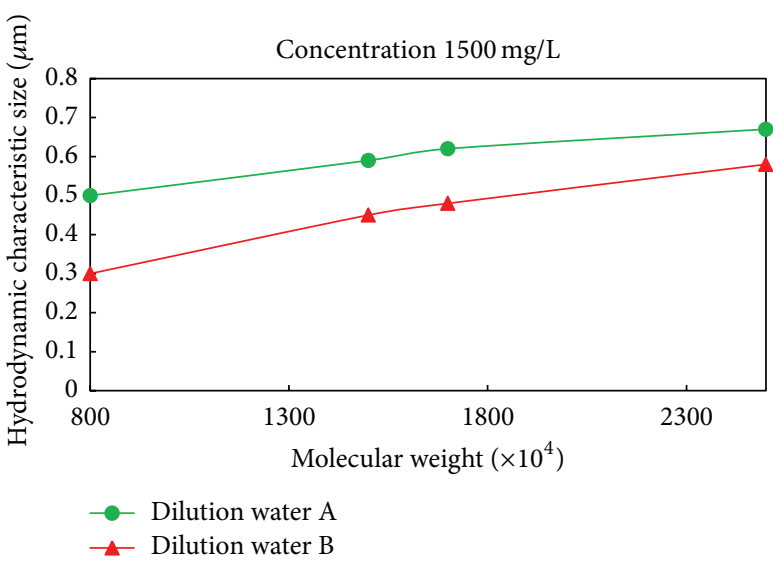

FIGURE 4: The hydrodynamic characteristic size increased as molecular weight rose.

matching relationship, pressure $0.05 \mathrm{MPa}$ was selected and all the following values were obtained under this standard.

Figure 4 illustrates the effect of the molecular weight of the polymer on the hydrodynamic characteristic size. The hydrodynamic characteristic size increased as the molecular weight increased. For instance, the size of the polymer with a concentration of $1500 \mathrm{mg} / \mathrm{L}$, diluted by dilution water $\mathrm{A}$, increased from $0.5 \mu \mathrm{m}$ to $0.67 \mu \mathrm{m}$ when the molecular weight increased from $800 \times 10^{4}$ to $2500 \times 10^{4}$. It was because the long chain and complex structures of the polymer with high molecular weight increased the probability of the polymer molecules winding in the aqueous solution.

Concentration of polymer was another factor. The hydrodynamic characteristic size increased obviously as the concentration of polymer solution increased, as presented in Figures 4 and 5 . The coils of the polymer molecules tended to be interspersed and overlap at a high polymer concentration, resulting in a bigger hydrodynamic characteristic size. 


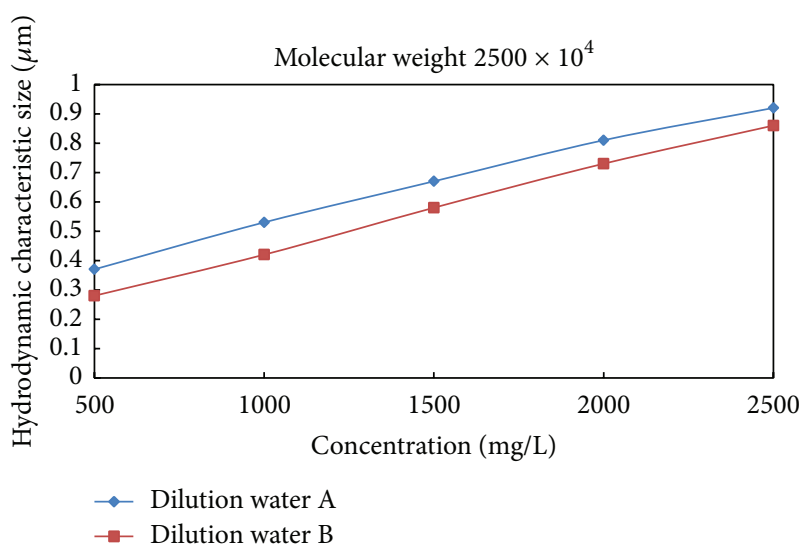

FIGURE 5: The hydrodynamic characteristic size increased obviously with the increase of concentration of polymer solution.

Besides, the hydrodynamic characteristic size of the polymer with high-salinity dilution water (dilution water B) was small compared with the size of the polymer diluted by low-salinity dilution water (dilution water A). This can be explained by the effect of cations in the water. Polyacrylamide chains shrunk because of salt's influence, resulting in a smaller hydrodynamic characteristic size.

Molecular weight and concentration of the polymer and the brine to prepare the polymer solution in the end affected the viscosity of polymer. As can be seen, a good nonlinear relationship between the viscosity of the polymer solution and the hydrodynamic characteristic size appears in Figure 6. The hydrodynamic characteristic size of polymer increased as the viscosity of polymer increased. Because the viscosity was a characteristic parameter of polymer and its close relation to the hydrodynamic characteristic size of polymer, the hydrodynamic characteristic size was named. The hydrodynamic characteristic size actually was the flow size of polymer during its seepage in the porous media.

\subsection{The Matching Relationship between the Hydrodynamic Characteristic Size of Polymer and Pore Throat Radius of Target Block $S$}

3.2.1. The Matching Relationship Criteria. In the target block $\mathrm{S}$, the formation fracture pressure gradient was $0.052 \mathrm{MPa} / \mathrm{m}$. During the polymer flooding period, the biggest flow pressure gradient must be lower than formation fracture pressure gradient; otherwise, the formation would be split. So the core matching relationship was selected as follows: good matching relationship was polymer flow pressure gradient lower than $0.052 \mathrm{MPa} / \mathrm{m}$; otherwise, it was bad.

The core flow experiments were conducted; the flow matching relationship plate was made in Table 3. Number 1 in the table means good matching. Number 0 means bad matching. The hydrodynamic characteristic size of polymer results is illustrated in Table 2. And pore throats radius of the natural cores obtained from natural core mercury injection curves from the target block $S$ is illustrated in Table 4 .

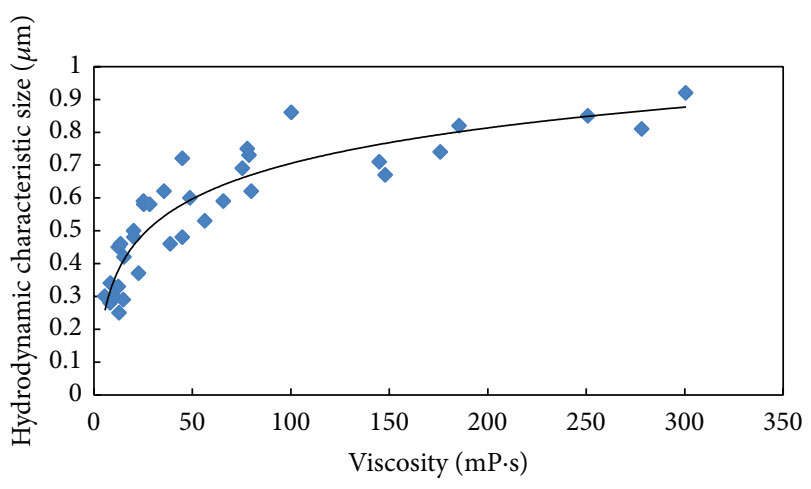

FIGURE 6: The hydrodynamic characteristic size maintained a good nonlinear relation with viscosity of polymer solution.

Carefully calculate the relationship rule in Table 2; it was found that good matching corresponded to the pore throat radius larger than 10 times the hydrodynamic characteristic size of polymer, and bad matching corresponded to the pore throat radius smaller than 10 times the hydrodynamic characteristic size of polymer. Thus, the multiples relationship summarized from the core flow studies in this study was 10 times.

3.2.2. The Hydrodynamic Matching Relationship Plates. Based on the matching multiples relationship obtained from the core flow studies, more hydrodynamic characteristic sizes of polymers were determined; together with the pore throat radius, the matching relationship plates between the hydrodynamic characteristic size and pore throat radius of the target block $S$ were established as illustrated in Tables 5-8. As can be seen, polymer with molecular weight more than 800 $\times 10^{4}$ and concentration more than $1500 \mathrm{mg} / \mathrm{L}$ did not match the formation with permeability lower than $337 \times 10^{-3} \mu \mathrm{m}^{2}$; only part of the polymers with low molecular weight and low concentration could make a good matching (Tables 5 and 6). With the permeability of the formation becoming larger, the polymer with larger hydrodynamic characteristic size gradually showed the good matching relationship (Table 7). When the permeability of formation was more than 928 $\times 10^{-3} \mu \mathrm{m}^{2}$, all the polymer solution studied in Table 2 (polymer with molecular weight ranged from $800 \times 10^{4}$ to $2500 \times 10^{4}$ and concentration ranged from $500 \mathrm{mg} / \mathrm{L}$ to $500 \mathrm{mg} / \mathrm{L}$ with two kinds of dilution water) showed the good matching relationship (Table 8).

\section{Conclusions}

The following conclusions could be drawn in this research.

(i) The hydrodynamic characteristic size of polymer can be determined by employing the microporous membrane filtration method. The value decreases as the pressure rises, so the experimental pressure should be determined according to the pressure of the target reservoirs. 
TABLE 2: The hydrodynamic characteristic size, $\mu \mathrm{m}$.

\begin{tabular}{|c|c|c|c|c|c|c|}
\hline \multirow{2}{*}{ Dilution water } & \multirow{2}{*}{ Molecular weight, $\times 10^{4}$} & \multicolumn{5}{|c|}{ Concentration, mg/L } \\
\hline & & 500 & 1000 & 1500 & 2000 & 2500 \\
\hline \multirow{4}{*}{ A } & 800 & $<0.22$ & 0.34 & 0.5 & 0.6 & 0.69 \\
\hline & 1500 & 0.25 & 0.46 & 0.59 & 0.71 & 0.82 \\
\hline & 1700 & 0.29 & 0.48 & 0.62 & 0.74 & 0.85 \\
\hline & 2500 & 0.37 & 0.53 & 0.67 & 0.81 & 0.92 \\
\hline \multirow{4}{*}{ B } & 800 & $<0.22$ & $<0.22$ & 0.3 & 0.46 & 0.58 \\
\hline & 1500 & $<0.22$ & 0.3 & 0.45 & 0.59 & 0.72 \\
\hline & 1700 & $<0.22$ & 0.33 & 0.48 & 0.62 & 0.75 \\
\hline & 2500 & 0.28 & 0.42 & 0.58 & 0.73 & 0.86 \\
\hline
\end{tabular}

TABLE 3: The core flow matching relationship plate.

\begin{tabular}{|c|c|c|c|c|}
\hline \multirow{2}{*}{ Dilution water } & \multirow{2}{*}{ Permeability, $\times 10^{-3} \mu \mathrm{m}^{2}$} & \multicolumn{3}{|c|}{ Molecular weight, $1500 \times 10^{4}$} \\
\hline & & Concentration, $1000 \mathrm{mg} / \mathrm{L}$ & Concentration, $1500 \mathrm{mg} / \mathrm{L}$ & Concentration, $2500 \mathrm{mg} / \mathrm{L}$ \\
\hline \multirow{5}{*}{ A } & 200 & 0 & 0 & 0 \\
\hline & 400 & 0 & 0 & 0 \\
\hline & 600 & 1 & 0 & 0 \\
\hline & 900 & 1 & 1 & 1 \\
\hline & 1200 & 1 & 1 & 1 \\
\hline \multirow{5}{*}{ B } & 200 & 0 & 0 & 0 \\
\hline & 400 & 1 & 0 & 0 \\
\hline & 600 & 1 & 1 & 0 \\
\hline & 900 & 1 & 1 & 1 \\
\hline & 1200 & 1 & 1 & 1 \\
\hline
\end{tabular}

(0 represents bad matching; 1 represents good matching).

TABLE 4: Pore throat parameters of target block S.

\begin{tabular}{lccc}
\hline Core number & Permeability, $\times 10^{-3} \mu \mathrm{m}^{2}$ & Porosity, \% & Pore throat radius, $\mu \mathrm{m}$ \\
\hline S1-1 & 204 & 25.5 & 2.43 \\
S1-2 & 337 & 29.30 & 2.95 \\
S1-3 & 661 & 31.70 & 5.47 \\
S1-4 & 928 & 28.01 & 9.26 \\
S1-5 & 1481 & 32.76 & 12.38 \\
\hline
\end{tabular}

TABLE 5: The matching relationship plate for reservoirs with permeability $204 \times 10^{-3} \mu \mathrm{m}^{2}$.

\begin{tabular}{|c|c|c|c|c|c|c|}
\hline \multirow{2}{*}{ Dilution water } & \multirow{2}{*}{ Molecular weight, $\times 10^{4}$} & \multicolumn{5}{|c|}{ Concentration, $\mathrm{mg} / \mathrm{L}$} \\
\hline & & 500 & 1000 & 1500 & 2000 & 2500 \\
\hline \multirow{4}{*}{ A } & 800 & 1 & 0 & 0 & 0 & 0 \\
\hline & 150 & 0 & 0 & 0 & 0 & 0 \\
\hline & 1700 & 0 & 0 & 0 & 0 & 0 \\
\hline & 2500 & 0 & 0 & 0 & 0 & 0 \\
\hline \multirow{4}{*}{ B } & 800 & 1 & 1 & 0 & 0 & 0 \\
\hline & 1500 & 1 & 0 & 0 & 0 & 0 \\
\hline & 1700 & 1 & 0 & 0 & 0 & 0 \\
\hline & 2500 & 0 & 0 & 0 & 0 & 0 \\
\hline
\end{tabular}

(0 represents bad matching; 1 represents good matching). 
TABLE 6: The matching relationship plate for reservoirs with permeability $337 \times 10^{-3} \mu \mathrm{m}^{2}$.

\begin{tabular}{|c|c|c|c|c|c|c|}
\hline \multirow{2}{*}{ Dilution water } & \multirow{2}{*}{ Molecular weight, $\times 10^{4}$} & \multicolumn{5}{|c|}{ Concentration, $\mathrm{mg} / \mathrm{L}$} \\
\hline & & 500 & 1000 & 1500 & 2000 & 2500 \\
\hline \multirow{4}{*}{ A } & 800 & 1 & 0 & 0 & 0 & 0 \\
\hline & 150 & 1 & 0 & 0 & 0 & 0 \\
\hline & 1700 & 1 & 0 & 0 & 0 & 0 \\
\hline & 2500 & 0 & 0 & 0 & 0 & 0 \\
\hline \multirow{4}{*}{ B } & 800 & 1 & 1 & 0 & 0 & 0 \\
\hline & 1500 & 1 & 0 & 0 & 0 & 0 \\
\hline & 1700 & 1 & 0 & 0 & 0 & 0 \\
\hline & 2500 & 1 & 0 & 0 & 0 & 0 \\
\hline
\end{tabular}

(0 represents bad matching; 1 represents good matching).

TABLE 7: The matching relationship plate for reservoirs with permeability $661 \times 10^{-3} \mu \mathrm{m}^{2}$.

\begin{tabular}{|c|c|c|c|c|c|c|}
\hline \multirow{2}{*}{ Dilution water } & \multirow{2}{*}{ Molecular weight, $\times 10^{4}$} & \multicolumn{5}{|c|}{ Concentration, $\mathrm{mg} / \mathrm{L}$} \\
\hline & & 500 & 1000 & 1500 & 2000 & 2500 \\
\hline \multirow{4}{*}{ A } & 800 & 1 & 1 & 1 & 0 & 0 \\
\hline & 150 & 1 & 1 & 0 & 0 & 0 \\
\hline & 1700 & 1 & 1 & 0 & 0 & 0 \\
\hline & 2500 & 1 & 1 & 0 & 0 & 0 \\
\hline \multirow{4}{*}{ B } & 800 & 1 & 1 & 1 & 1 & 0 \\
\hline & 1500 & 1 & 1 & 1 & 0 & 0 \\
\hline & 1700 & 1 & 1 & 1 & 0 & 0 \\
\hline & 2500 & 1 & 1 & 0 & 0 & 0 \\
\hline
\end{tabular}

(0 represents bad matching; 1 represents good matching).

TABLE 8: The matching relationship for reservoirs with permeability more than $928 \times 10^{-3} \mu \mathrm{m}^{2}$.

\begin{tabular}{|c|c|c|c|c|c|c|}
\hline \multirow{2}{*}{ Dilution water } & \multirow{2}{*}{ Molecular weight, $\times 10^{4}$} & \multicolumn{5}{|c|}{ Concentration, mg/L } \\
\hline & & 500 & 1000 & 1500 & 2000 & 2500 \\
\hline \multirow{4}{*}{ A } & 800 & 1 & 1 & 1 & 1 & 1 \\
\hline & 150 & 1 & 1 & 1 & 1 & 1 \\
\hline & 1700 & 1 & 1 & 1 & 1 & 1 \\
\hline & 2500 & 1 & 1 & 1 & 1 & 1 \\
\hline \multirow{4}{*}{ B } & 800 & 1 & 1 & 1 & 1 & 1 \\
\hline & 1500 & 1 & 1 & 1 & 1 & 1 \\
\hline & 1700 & 1 & 1 & 1 & 1 & 1 \\
\hline & 2500 & 1 & 1 & 1 & 1 & 1 \\
\hline
\end{tabular}

(0 represents bad matching; 1 represents good matching).

(ii) The hydrodynamic characteristic size is closely related to the viscosity of the polymer solution. The molecular weight, the concentration of the polymer solution, and the dilution water can affect the viscosity of the polymer so as to affect the hydrodynamic characteristic size of polymer.

(iii) The matching relationship criteria can be drawn from the natural core flow experiments; good matching relationship between polymer and formation was identified as the flow pressure gradient lower than the fracture pressure gradient of the formation. The multiples relationship calculated from the core flow experiments in this study was 10 times. Polymer with 10 times the hydrodynamic characteristic size less than the pore throat size can well match the formation.

(vi) Generalize the matching relationship obtained from the core flow studies; matching relationship between polymer with molecular weight ranged from $800 \times 10^{4}$ to $2500 \times 10^{4}$, concentration ranged from $500 \mathrm{mg} / \mathrm{L}$ to $2500 \mathrm{mg} / \mathrm{L}$ with two kinds of dilution water, and the formations with different permeability of the target block $\mathrm{S}$ in this study were obtained.

(v) This method to research the matching relationship between the chemical solutions and formations can be 
used to any target block; matching criteria can be different according to the hydrodynamic characteristic size of the chemicals and the formation information. The matching criteria will be more accurate with more core flow experiments being conducted.

\section{Conflict of Interests}

The authors declare that there is no conflict of interests regarding the publication of this paper.

\section{Acknowledgments}

The authors would like to thank Professor Kang Wanli of China University of Petroleum, Beijing for providing guidance and ideas to this study. The experiments were partly performed by Liu Shaopeng, Lv Xiuqin, Yang Shanshan, Xiang gang, and Miao Junjie. Thanks are due to all the colleagues who have contributed to this paper in enhanced oil recovery of the China University of Petroleum, Beijing.

\section{References}

[1] D. J. Pyesym, "Improved secondary recovery by controlling the water mobility," Journal of Petroleum Technology, vol. 16, no. 8, pp. 911-916, 1964.

[2] B. B. Sandiford, "Flow of polymers through porous media in relation to oil displacement," in Proceedings of the Improved Oil Recovery Symposium of AICHE, Paper No. 40b, Kansas City, Mo, USA, April 1976.

[3] M. T. Szabo, "Evaluation of water-soluble polymers for secondary oil recovery-1," JPT, Journal of Petroleum Technology, vol. 31, no. 5, pp. 553-560, 1979.

[4] M. T. Szabo, "Evaluation of water-soluble polymers for secondary oil recovery-2," JPT, Journal of Petroleum Technology, vol. 31, no. 5, pp. 561-570, 1979.

[5] C. Jiecheng, "Molecular weight optimization for polymer flooding," Acta Petrolei Sinica, vol. 21, no. 1, pp. 102-106, 2000.

[6] Z. Yunlai, "Adaptability of EOR polymers to sandstone reservoirs of intermediate to high permeability in Jiangsu oil fields," Oilfield Chemistry, vol. 25, no. 3, pp. 245-248, 2008.

[7] X.-G. Lu and Z.-H. Gao, "Pore throat radius to coil gyration radius ratio as characteristic of adaptivity of polymer molecular mass to core permeability," Oilfield Chemistry, vol. 13, no. 1, pp. $72-75,1996$.

[8] L. Weili, N. Xiaobin, L. Meiqin, and L. Qingxia, "Study on matching relation between polymer molecular size and pore size for conglomerate reservoir," IPTC16660, 2013.

[9] L. Meiqin and Z. Qingquan, "Matching relation between partially hydrolyzed polyacrylamide and nuclear pore membrane," Petrochemical Universities, vol. 25, no. 2, pp. 42-47, 2012. 

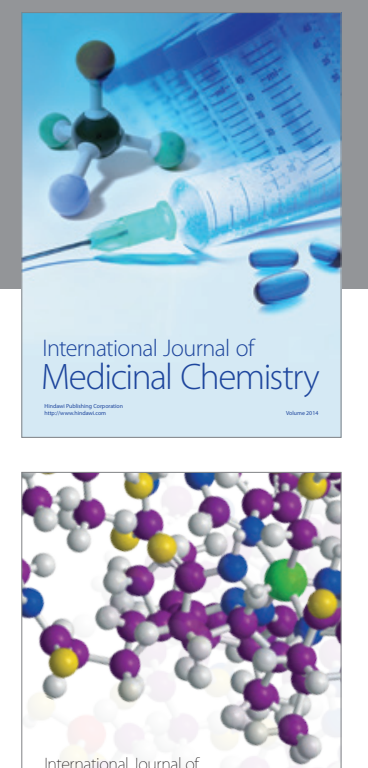

\section{Carbohydrate} Chemistry

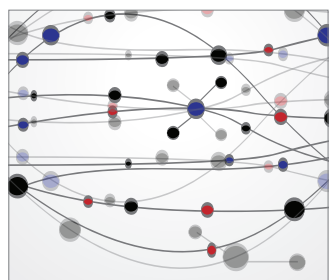

The Scientific World Journal
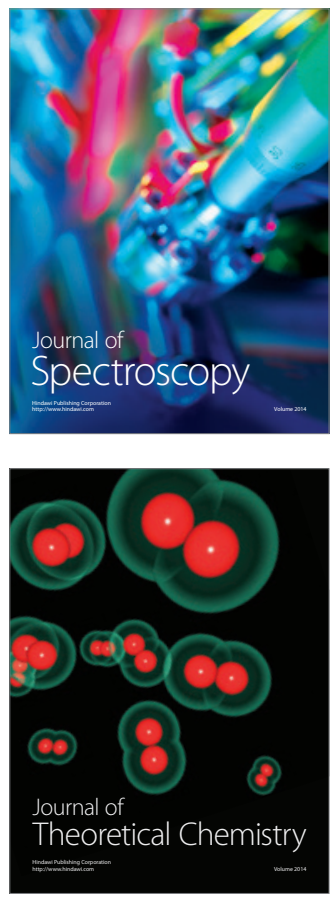
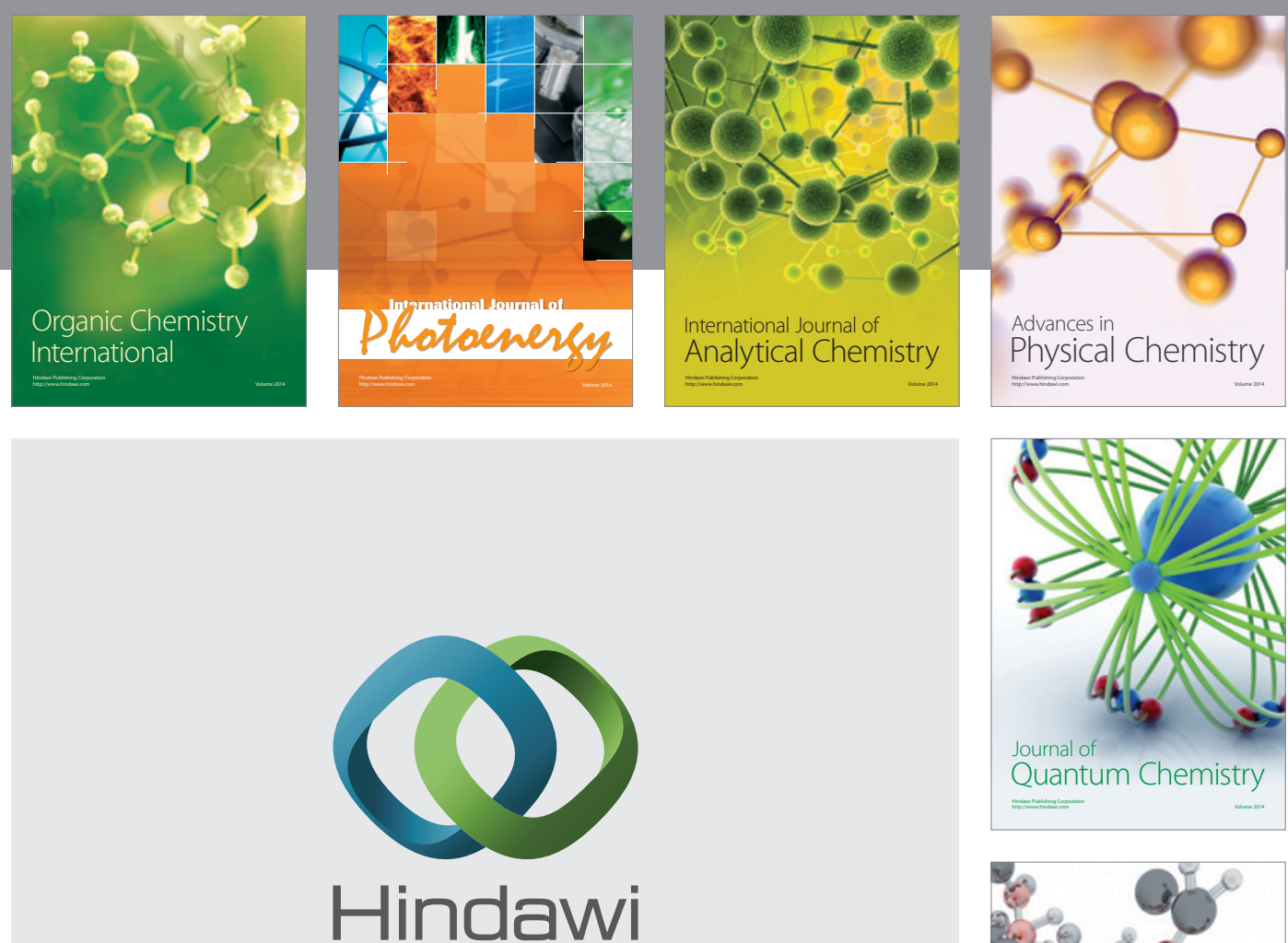

Submit your manuscripts at

http://www.hindawi.com

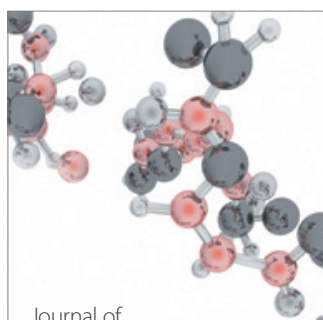

Analytical Methods

in Chemistry

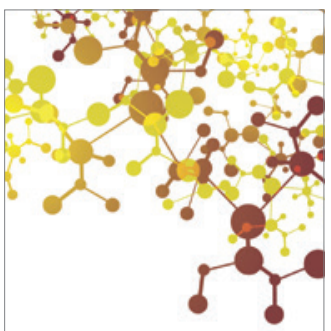

Journal of

Applied Chemistry

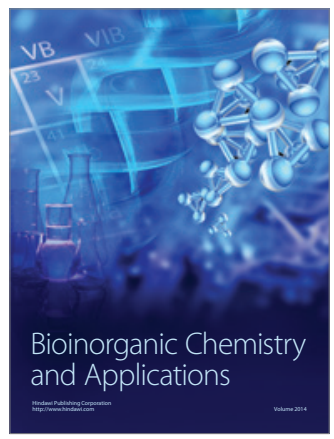

Inorganic Chemistry
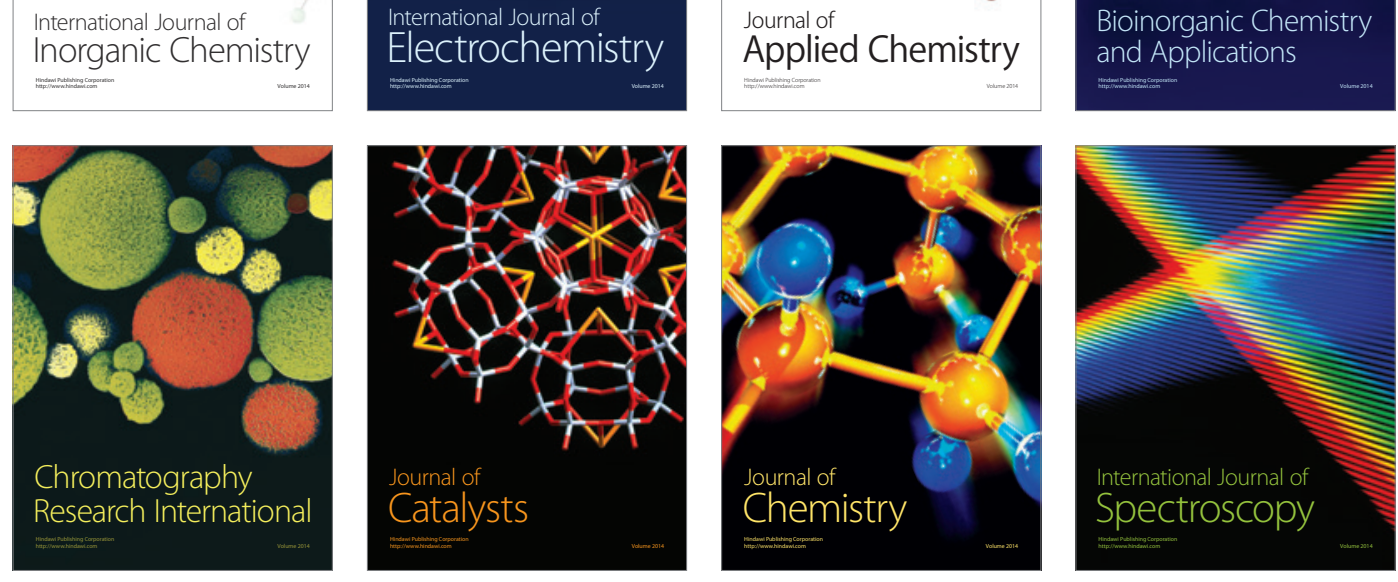